\title{
Effective Community Listening: A Case Study on Photovoice in Rural Nicaragua
}

\author{
Ali Aslam* \\ Civil Engineering \\ University of Virginia \\ Charlottesville, VA 22904 \\ aa9af@virginia \\ Rachel Boots \\ Civil Engineering \\ University of Virginia \\ Charlottesville, VA 22904 \\ rwb4pq@virginia.edu \\ Sara Link \\ Civil Engineering \\ University of Virginia \\ Charlottesville, VA 22904 \\ sdl6dt@virginia.edu
}

\author{
Matthew Pearson-Beck* \\ Computer Engineering \& Computer Science \\ University of Virginia \\ Charlottesville, VA 22904 \\ mjp2ff@virginia.edu \\ Holly Mayton \\ Chemical Engineering \\ University of Virginia \\ Charlottesville, VA 22904 \\ hmm7cs@ virginia.edu
}
Dana Elzey, Dr. rer. Nat.
Materials Science \& Engineering University of Virginia
Charlottesville, VA 22904 dme2j@virginia.edu

*These authors contributed equally to this paper.

\begin{abstract}
Before beginning a service learning project, students and researchers must listen to the communities with whom they intend to work. By engaging in practical community listening activities, researchers can better understand local culture and effectively solicit a community's development needs. Photovoice is a simple method that can be applied in service learning projects to help researchers understand the realities associated with their partner community. For service learning projects in unfamiliar settings, researchers should work closely with an experienced partner organization that understands the community's customs and culture. Applying Photovoice to development projects will facilitate problem identification, promote community empowerment, and assist in developing mutuallybeneficial partnerships. Photovoice creates a platform within a community for candid discussion about relevant issues, challenges, and needs for community-based development. In addition to improving the sustainability of service learning community partnerships, these activities enhance the resiliency of the projects that develop through community empowerment. This article outlines the significance of community listening in service learning projects and provides a case study of the Photovoice method that student researchers used when engaging with a rural Nicaraguan community.
\end{abstract}

Index Terms - Nicaragua, Photovoice, community listening, service learning

\section{INTRODUCTION}

During the summer of 2012, five undergraduate engineering students from the University of Virginia (UVa) began collaborating with the rural Nicaraguan community of Rosa Grande to establish a sustainable service learning partnership. The team of student researchers also 
partnered with Bridges to Community (BTC), a trusted non-governmental organization (NGO) with an existing presence in the region. Engineering Students Without Borders, a student-run organization at UVa, has an established relationship with BTC. This partnership assisted the research team in identifying opportunities for further development of community-based projects. BTC's experience with community organizing in Nicaragua improved the effectiveness of the students' communication and engagement with community members. The mutually beneficial partnership that was established amongst all three stakeholders - student researchers, BTC, and Rosa Grande - has led to valuable outcomes for all who were involved.

Before beginning any service learning activities, it is important for all students and researchers to listen to the communities in which they intend to work. ${ }^{\mathrm{i}}$ Listening is an active form of research that involves the mindful collection of data to identify inherent characteristics of a community. This article provides a case study of the Photovoice method that student researchers used when engaging with the community of Rosa Grande. In addition to defining the Photovoice method, the authors provide an overview of its effectiveness as a community listening tool and how it was applied to identify pertinent needs of the Rosa Grande community.

\section{The Importance of Community Listening In Service Learning Projects}

In the context of international engineering projects, especially for those incorporating service learning, it is crucial that any proposed solutions address needs that are expressed directly by the community rather than those identified by outsider perspectives. ii Clapperton Mavhunga, Assistant Professor of Science, Technology and Society at Massachusetts Institute of Technology, states, "The time of lecturing rural people on what they need and should want is over; these people know their problems and have ideas about solving them." "iii Unfortunately, these ideas are often unheard or disregarded as engineers still attempt to solve problems in international settings without engaging communities or understanding cultures. This can lead to unsustainable and ineffective solutions, and after several "failed" attempts, community members may feel exhausted and over-researched. ${ }^{\text {iv }}$ Most participants in service learning projects have good intentions, but their actions stray from their altruistic motivations when partnerships unilaterally benefit researchers. Extractive relationships involving researchers, engineers, and community partners are explained through the phenomenon of "mosquito" scientists and "parachuting" consultants, where researchers enter and exit a community without engaging the community to develop sustainable solutions. ${ }^{\mathrm{V}}$

In service learning projects, the student researchers' objectives should be aligned with community needs and desires. As a collective educational experience for both students and community members, service learning projects provide unique opportunities to bring mutually beneficial and sustainable outcomes through engaged collaboration. ${ }^{\text {vi }}$ For researchers, it is important to recognize their own roles and understand that they do not have all of the answers to a given problem. The educational value of service learning is demonstrated through the creation of useful knowledge through the hands-on learning process that students and communities experience together. To promote sustainability of service learning initiatives, it is therefore imperative to actively listen to community partners and solicit their input before designing any solutions. ${ }^{\text {vii }}$ There are many examples of projects that have ended with unintended consequences due to a lack of communication between researchers and community partners. For instance, an environmental health project implemented in East Timor constructed water supply and sanitation facilities for local communities, but upon completion of the project it was discovered that the 
facilities were not being used. This was attributed to a misunderstanding of community needs and a lack of community involvement in the planning stage of the project. ${ }^{\text {viii }}$ Projects like this result in wasted time and resources due to a simple failure to listen to the community prior to implementing technologies. Listening to community members provides useful information for design considerations, while soliciting input promotes a greater sense of community ownership over a project, which further improves its usefulness and sustainability. ${ }^{\text {ix }}$

\section{Defining Photovoice}

Photovoice is a participatory action research method that allows participants to express their opinions by capturing photographs representing significant themes in and around their community. The concept of Photovoice was originally developed in 1992 by Caroline C. Wang and Mary Ann Burris to empower women in Chinese villages to voice their everyday hardships. ${ }^{\mathrm{X}}$ Photovoice was created with three main goals: 1) record and represent everyday realities, 2) promote critical dialogue and share knowledge about personal and community strengths and concerns, and 3) reach policy-makers. ${ }^{\text {xi }}$ Photovoice follows a specific 9-step process (Figure 1).

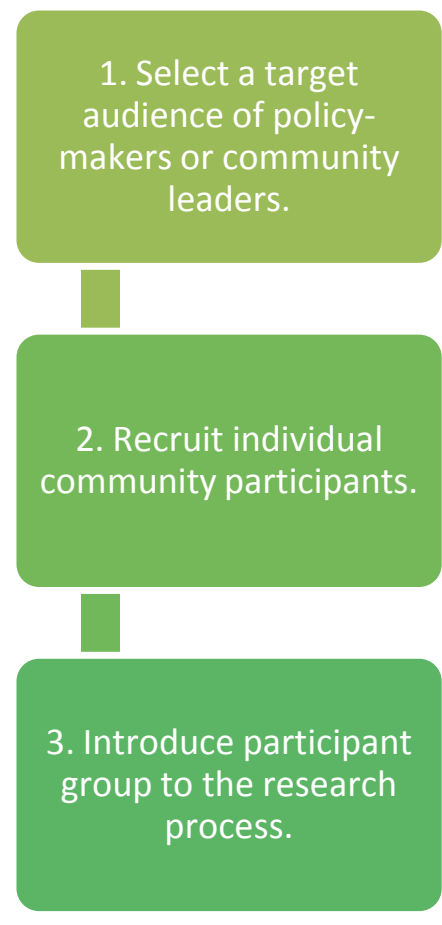

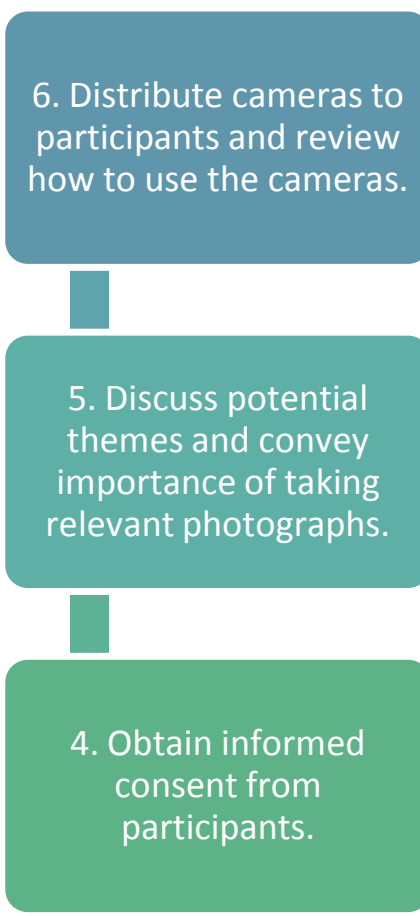

FIGURE 1

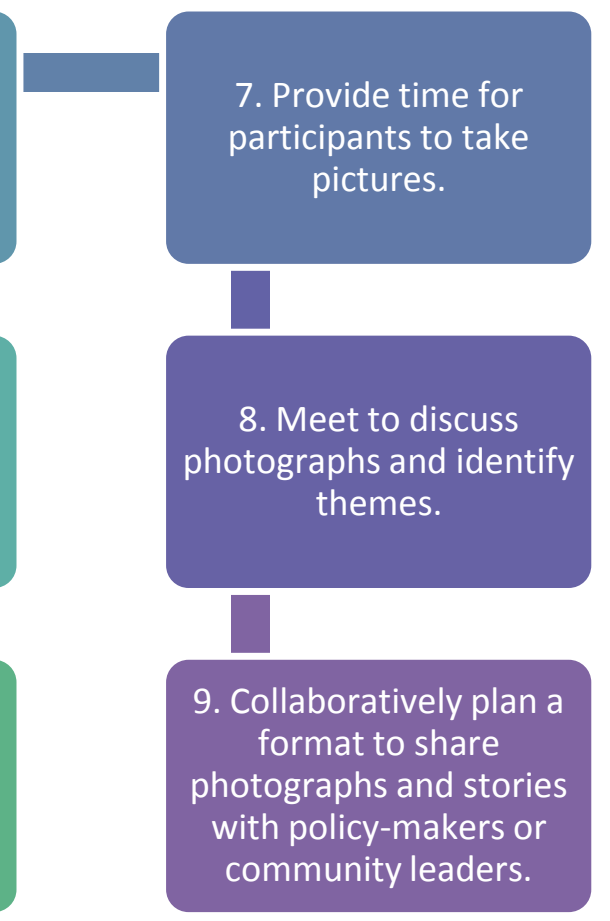

WANG’S NINE STEP PROCESS FOR EFFECTIVE COMMUNITY LISTENING WITH PHOTOVOICE

These nine steps are intended to provide a public stage on which the community's voices can be heard and considered by groups, such as NGOs and policy-makers, who are able to facilitate positive development. 


\section{Relevance of Photovoice for Service Learning}

When entering into an unfamiliar community with an intention to improve some aspect of community members' lives, researchers should be wary of their actions and strive to maintain a

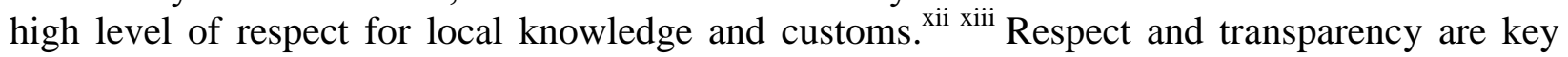
components for promoting trust and mutuality in an effective partnership. The Photovoice method is designed to promote social change through respectful engagement between researchers and community members while effectively eliciting individuals' opinions. ${ }^{\text {xiv }}$ The Photovoice method is useful for researchers wishing to begin service learning partnerships in unfamiliar communities; researchers are presented with an effective tool to listen to a community while gaining an understanding of the local realities where they intend to work.

The rural location and impoverished socioeconomic status of Rosa Grande - similar to many other service learning project settings- made it culturally appropriate to use Photovoice. ${ }^{\mathrm{xv} \text { xvi }}$ Since Photovoice is a visually engaging research process, it is applicable in communities with low participant education levels. ${ }^{\text {xii }}$

\section{Use of Photovoice in Rosa Grande}

The research team's partnership with Rosa Grande intentionally took place during BTC's extended presence in the region. Before partnering with Rosa Grande, BTC confirmed that the community had strong leadership, an organized community structure, and a need for substantial development work. The community also expressed an interest in forming a partnership and was very receptive to external aid. The community, research team, and BTC all had similar goals of sustainable development and collaborative community engagement, so a written mutual agreement was established and a service learning partnership was formed. This partnership allowed each stakeholder to derive valuable benefits: The community gained access to capacitybuilding resources, the researchers gained hands-on engineering research and development experience, and the NGO community partner gained additional techniques for evaluating its programs in the region.

Photovoice is an effective method for achieving the goals listed above. ${ }^{\text {xviii }}$ Because of this, it was identified as the most appropriate method for community listening. In Rosa Grande, the community's organized leadership structure facilitated participation and discussion amongst community members. Rosa Grande's receptiveness to an outside presence also allowed Photovoice to be employed as a means for assessing the inherent needs of the community and its desires for future development. ${ }^{\text {ix }}$

After discussing the Photovoice project with the community leader and reaching out to potential participants throughout the community, the first meeting was held. The initial meeting took place at the secondary school, a central location in the community, and all community members interested in participating were invited. Researchers introduced themselves to the Photovoice participants, distributed used digital cameras, and taught participants the basic camera functions they would be using. With the help of BTC personnel, the research team explained the importance of taking photographs that were relevant to each individual participant and to the community as a whole (Figure 2). The significance of the project was made clear to participants, and formally-documented verbal consent was given by each participant before any photographs were taken. 


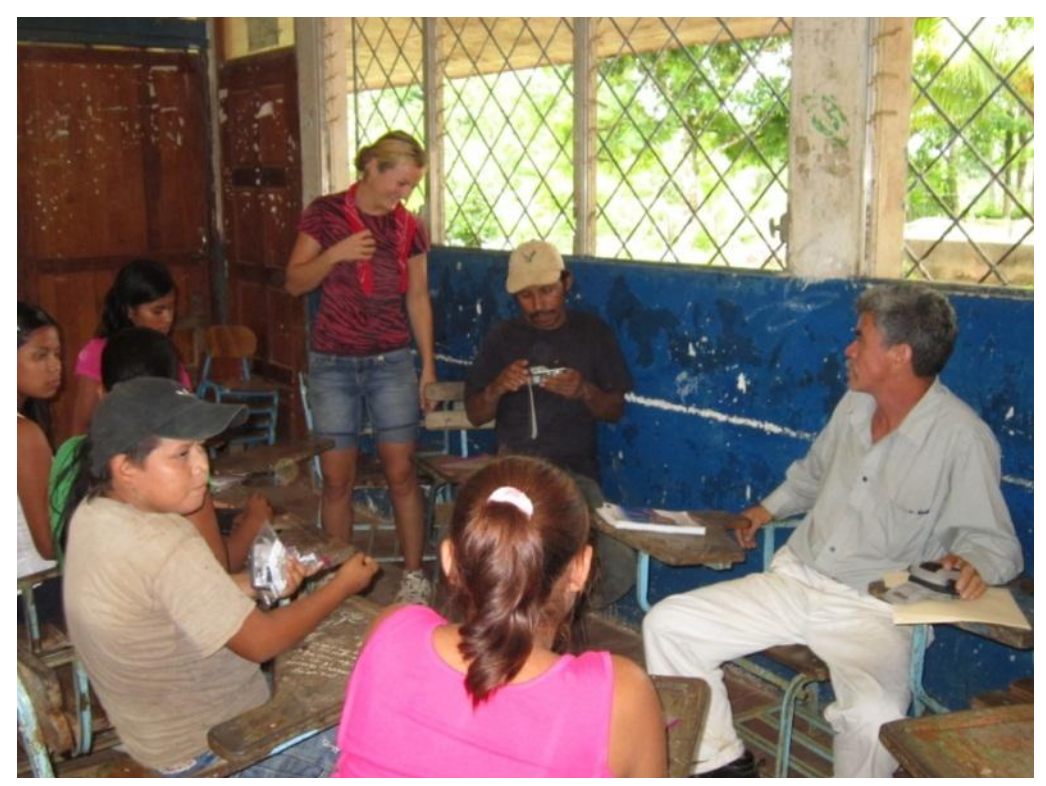

FIGURE 2

PARTICIPANTS ARE TAUGHT HOW TO USE CAMERAS AT THE FIRST PHOTOVOICE MEETING.

There were a total of thirteen cameras distributed, and the participants were given five days to independently take photographs. The photographs were meant to represent community features that were important to certain individuals, were in need of improvement, or were significant to Rosa Grande as a whole. The participants each took an average of twelve photographs. After this data collection period, participants met with the research team for individual interviews about their photographs. Participants were asked to describe the relevance of each photograph on their cameras, select what they considered to be the two most important photographs, and provide a caption for each of the photographs selected.

The photographs chosen by each of the participants were printed and displayed in a photo show at the third and final Photovoice meeting (Figure 3). At the photo show, several participants indicated that they had found the Photovoice experience rewarding. The entire community, including the community leaders, was invited to the school to view and discuss the photographs that were taken during the project. Each Photovoice participant was given the opportunity to present his or her two photographs, and explain why the represented topics were important to the community. The presentations were then allowed to naturally progress into a community discussion, led by the community leader, with additional support from BTC personnel. This discussion identified important issues that affected the community of Rosa Grande and its members. The four major themes identified were water quality, residential infrastructure, environmental degradation, and educational and recreational facilities. 


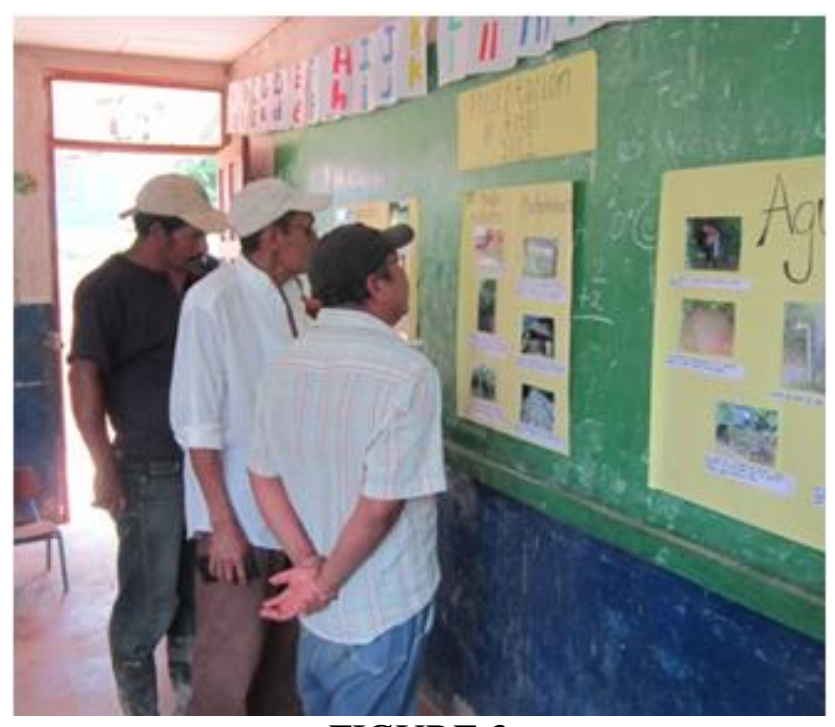

FIGURE 3

COMMUNITY MEMBERS VIEW PICTURES AT THE PHOTO SHOW.

As a result of these identified themes, community members formed two committees to look further into the issues. At the time of the researchers' departure from Rosa Grande, community efforts were already underway. Another team of undergraduate researches from UVa is returning to Rosa Grande and is working with the community in developing solutions to their selfidentified issues.

The results from the Photovoice discussion benefitted the community and facilitated the research team's problem identification and design generation process. By using Photovoice to engage and collaborate with the community, the research team was able to encourage participants to take initiative in organizing future development projects. Because the community members identified the issues themselves, they were empowered to begin developing resilient solutions. ${ }^{\mathrm{xx}}$ Using Photovoice to engage and collaborate with the community, the research team was able to encourage participants to take initiative in organizing future development projects.

Working with an NGO community partner like BTC minimized restrictions, such as language barriers and cultural differences, which otherwise would have prevented candid discourse between community members and the research team. Translators were utilized to overcome the language barrier, and since BTC was familiar with the local geography the project was not restricted by logistical challenges such as finding meeting locations. BTC also understood the culture and customs of Rosa Grande very well and could facilitate community discussions. Fewer restrictions allowed for more diversity in participant selection, and so community demographics were more accurately represented.

Partnering with BTC also impacted the outcomes of Photovoice. Having an outside party review the results of the Photovoice research helped verify that the outcomes would influence the development of sustainable projects. ${ }^{\text {xi }}$ BTC's year-round presence facilitated the community's access to the research results while they began to develop useful projects. ${ }^{\text {xxii }}$ This created a greater sense of project ownership within the community. Established in-country organizations like BTC are able to identify additional stakeholders and send research data to policymakers, other NGOs, university communities, and other local communities that can provide additional assistance to a given service learning community development project. 


\section{Specific Benefits of Photovoice}

The researchers identified specific benefits of using Photovoice in Rosa Grande that could be translated to other projects in similar contexts (Figure 4). These illustrated benefits are explained in more detail below.

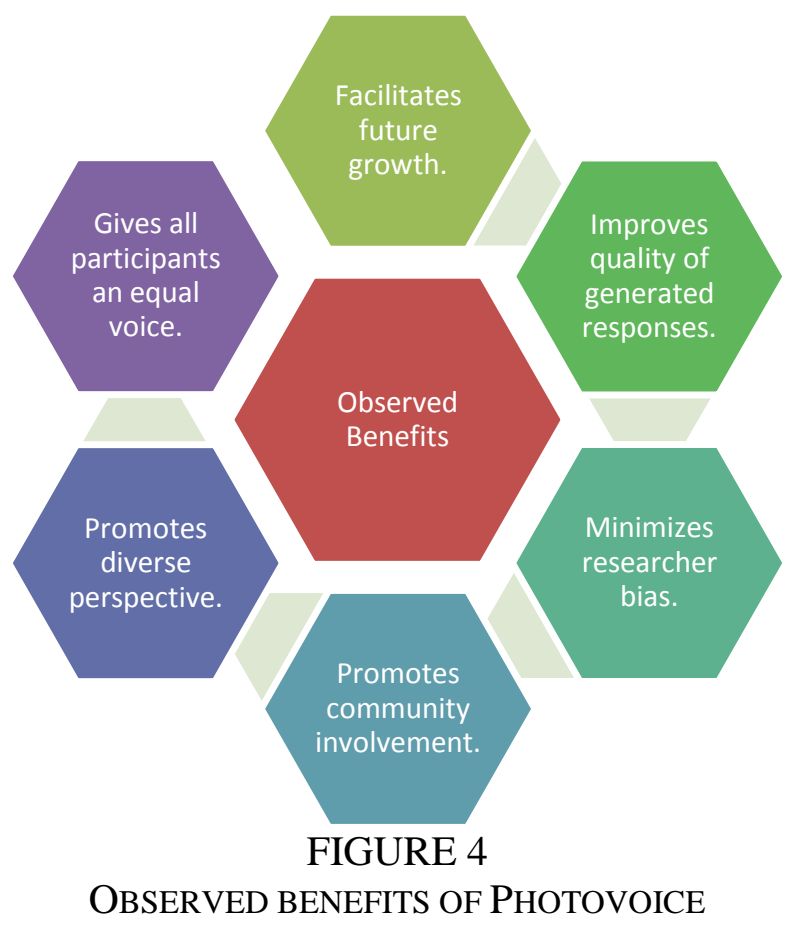

Photovoice evokes a community's perspective on relevant development issues through a process that improves the quality of generated responses. Unlike discussion in focus groups where community members may feel uneasy speaking about sensitive topics, Photovoice avoids social stigmas by allowing community members to visually communicate themes. ${ }^{\text {xiii }}$ The use of images and visual aides also minimizes limitations caused by vague phrasing of verbal statements. The photographs help to reduce arguments or stagnation that can stem from verbal discussion between community members.

Photovoice gives an equal voice to each participant, and thus minimizes the risk of one community member dominating the conversation. With Photovoice, participants present their photographs to the community, followed by a discussion that is open to the entire community. ${ }^{\text {xxiv }}$ In a more traditional community discussion, one individual may dominate the conversation and dissuade others from speaking, therefore biasing what the researchers perceive to be an accurate representation of the whole community. ${ }^{\mathrm{xx}}$

Researchers can use the results to facilitate future development and initiate new projects by using the discussed topics as indicators of the needs that the community considers to be most pertinent. As a method of problem identification, Photovoice minimizes researcher bias. Social research, if done incorrectly, negates how people view themselves as active members of society. ${ }^{\text {xxvi }}$ Photovoice allows community members to identify their issues through photographs that are open to interpretation by the community at large. In an open-forum discussion facilitated 
by community leaders, the researchers take a backseat to the community and allow community members to identify their own needs without biasing the results.

Researchers should select Photovoice participants such that the participant group is representative of a community's demographic diversity. The participant pool should be chosen such that a variety of voices with respect to age, gender, race, socioeconomic status, and levels of influence within the community all may be heard. In the opinion of the researchers, this allows for a more accurate assessment of the communities' beliefs and better determination of how to address them. Issues may arise in some cultures that tend to give more weight to opinions of certain groups in comparison to others in a community. ${ }^{\text {xxvii }}$ Photovoice respects community ideals, allowing researchers to consider ingrained cultural inequalities and fairly represent the needs of different groups in a community. ${ }^{\text {xxviii }}$

Photovoice also promotes community involvement in research, design, development, and implementation of generated solutions. The community members become the driving force in identifying their own needs, and therefore have a greater stake in recognizing challenges beyond simply being affected by them. ${ }^{\text {xxix }}$ The community-wide discussion serves not only to identify needs but also to motivate the community to guide the project's success after the researchers' departure. $^{\mathrm{xxx}}$

\section{Alternative and Supplemental Methods}

Photovoice may not be a suitable research technique for community listening in all service learning projects. Other participatory research methods may be used to supplement Photovoice or may be used in its place; these include individual interviews and focus groups. As explained in detail below, each of the three methods has its own unique features and benefits (Figure 5).

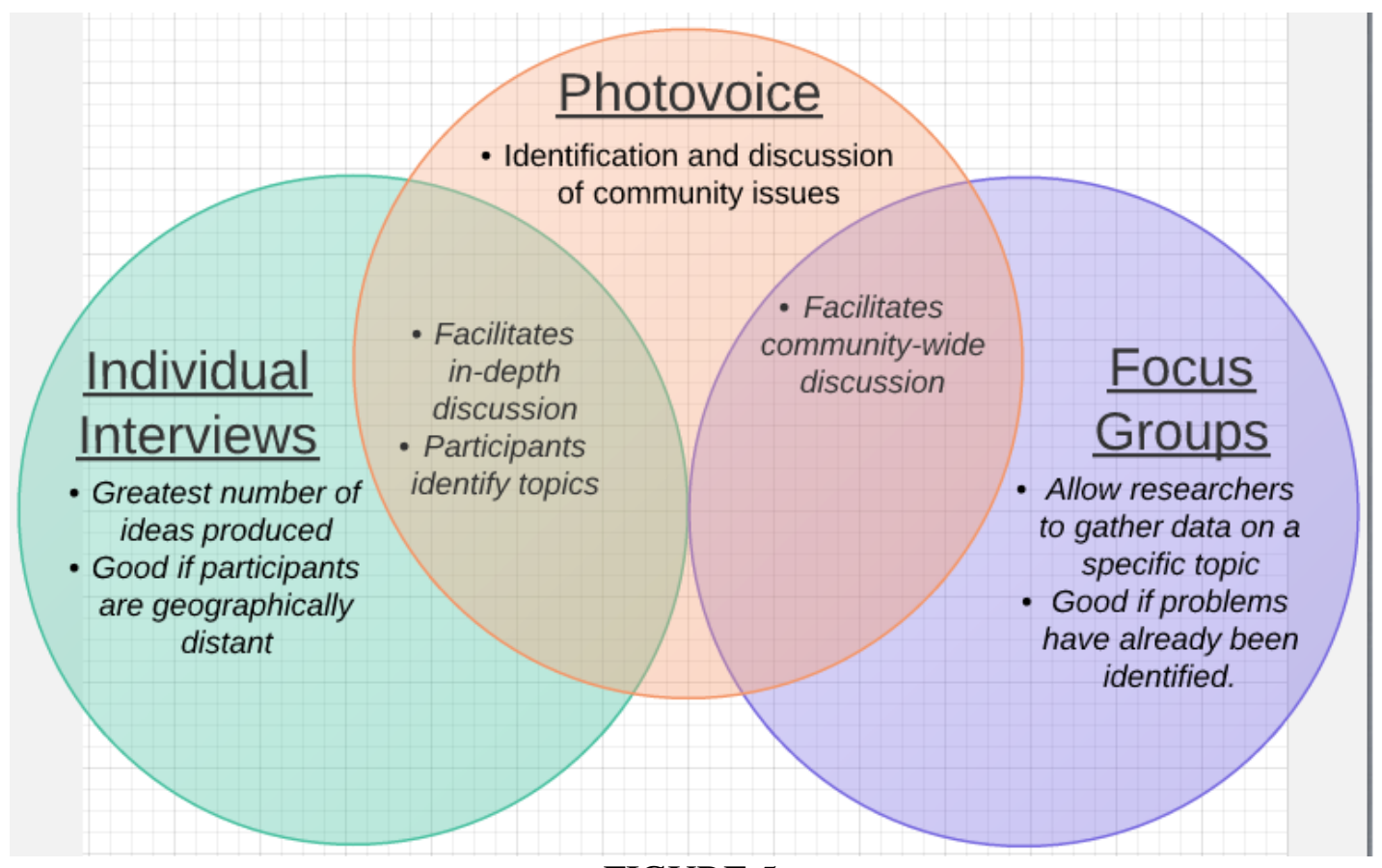

FIGURE 5

MODIFIED VENN DiAgRAM SHOWING HOW PHOTOVOICE INCLUDES ALTERNATIVE METHODS OF COMMUNITY LISTENING. 
Focus groups are led by a moderator to generate group discussion on a specific topic. ${ }^{\mathrm{xxi}} \mathrm{A}$ researcher assembles a group of five to ten community members and asks the group to brainstorm ideas on specific subjects. ${ }^{\text {xxii }}$ By their nature, focus groups create group discussion centered on the topics chosen by the researcher. It is the researchers' opinion that focus groups would be a reliable community listening activity for service learning projects that aim to obtain focused results in pre-determined areas.

Like focus groups, an individual interview is led by a researcher. Individual interviews with community members produce significantly more ideas than focus groups. ${ }^{\text {xxiii }}$ One-on-one interviews give the participants the opportunity to voice their concerns freely and develop more in-depth personal ideas than in focus groups. Individual interviews do not involve a community or group discussion component and therefore will give the researcher the ability to direct the discussion. Often times, community members are geographically spread too far or are too busy to commit to many scheduled group meetings, in which case individual interviews provide an effective method for obtaining useful information.

Photovoice is flexible because it allows researchers to carry out a significant amount of concurrent research. Based on the researchers' observations, much of the time required for a Photovoice project involves waiting for participants to take photographs and setting meeting times that will accommodate participants' busy schedules. Between the major deadlines of a Photovoice project, there are substantial time intervals that can be used for other research or work. For example, Photovoice research in Rosa Grande was conducted concurrently with GIS mapping and the assessment of municipal water quality, as well as ongoing construction projects throughout the community.

In the case of the project in Rosa Grande, the research team saw Photovoice as an ideal combination of both individual interviews and focus groups. Based on the features of each methodology, Photovoice allows community members to identify the issues and then discuss them amongst themselves, with only loose facilitation provided by the researchers.

\section{IMPLICATIONS ON TRANSFORMATIVE DEVELOPMENT AND SUSTAINABILITY}

The Photovoice project served as a platform on which voices throughout the community of Rosa Grande where amplified and heard amongst other community members. Photovoice is a useful participatory research approach because of its ability to create direct benefits for those involved in the research process. ${ }^{\text {xxiv }}$ It was important for the research team to recognize their roles as outsiders who did not have the right to dictate community affairs. The researchers stepped back and allowed the community to take leadership over the project's outcomes. Consequently, when the community members were presented with the opportunity to autonomously lead their own development efforts, they embraced the opportunity. During the open-forum, Photovoice participants and other community members volunteered to form small committees to organize development initiatives within their community. Participants who took photographs and other community members who participated in group discussions became part of a community-based movement.

It was apparent that once the community was presented with the opportunity to lead development efforts, it would readily accept this offer and actively progress as long as it was well-equipped to do so. ${ }^{\text {xxv }}$ Offering to aid in building a community's capabilities is much more conducive to sustainable community development than offering to implement an arbitrary technology to meet the same need. ${ }^{\mathrm{xx} x \mathrm{i}}$ Researchers must work with the community to devise a 
plan for capacity-building, although it may be tempting to just implement a complex technological solution. ${ }^{\text {xxxii }}$ If the research team can listen effectively throughout the process of engaging the community, then areas of need within the community will become apparent.

Through the Photovoice process in Rosa Grande, the research team received information about the community's needs and challenges, and the community gained an alternative view and understanding of its own priorities. This was evident from conversations with community members, in which some stated their appreciation of the participants' diverse viewpoints. Not only were there passionate discussions regarding community needs, but several advocates emerged from the group willing to work toward creating community-based solutions to the challenges that were identified. Through the open-forum, community members took leadership roles to start working towards positive change.

In addition to being a tool for community listening, Photovoice empowered the Rosa Grande community by increasing relational opportunities and transforming individual and community insights into community-wide social ideals. ${ }^{\text {xxviii }}$ Those who stood up during the final Photovoice discussion showed qualities of understanding, commitment, and skill. These are all necessary traits for strengthening the community's ability to address present and future challenges. ${ }^{\text {xxix }}$ When community members have the knowledge and skills necessary to improve their community, they will be empowered through access to the resources necessary to pursue positive community development. This process of increasing opportunities leads to the beginnings of transformative development within a community. The knowledge and skills that are necessary for a community to begin solving its own problems can be acquired through a process of reciprocal empowerment and increased opportunities whereby researchers listen to a community's concerns and offer resources that are mutually beneficial. ${ }^{\mathrm{xl}}$ In order to increase the sustainability of long-term projects, researchers should develop a project with the community partner who is most affected, and ultimately transfer ownership to that partner. By listening, engaging, and collaborating on project designs and activities, communities will be empowered to take responsibility and continue working and improving even after researchers leave. ${ }^{x l i}$

\section{CONCLUSION}

Community listening is a vital aspect of service learning projects, but it is often over-looked. Although problem identification can be accomplished using a few different methods, it is important that the process proceeds in an unbiased manner to solicit the inherent needs of a community. Photovoice can be used as an effective tool for community listening because of its ability to create a platform within the community for candid discussion about issues that may otherwise not be discussed. The visual aspect of Photovoice allows community members to express themselves in a unique way that enables researchers to hear perspectives from different demographics in the community. The Photovoice methodology works especially well in international contexts because the use of photographs facilitates communication between researchers and participants and helps to mitigate cultural and linguistic misunderstanding. Students interested in participating in engineering service learning projects should consider using Photovoice as a means for listening and understanding a community before designing solutions. When engaging in community listening activities, whether or not Photovoice is involved, sustainability of projects is improved through collaborative design processes and community empowerment. 


\section{ACKNOWLEDGMent}

The authors would like to thank their faculty advisor, Dana Elzey, at UVa. Additionally, they would like to thank the Engineering Students Without Borders organization at UVa for coordinating and providing resources to facilitate the research project throughout all stages. Finally, the authors would like to thank Bridges to Community in Nicaragua for their continued support in making this research possible. Financial support was provided by the Lacey Fund, the UVa Travel and Activities Fund, the UVa Innovation in Public Service Pitch Competition, and individual private donors.

\section{ENDNOTES AND REFERENCES}

\footnotetext{
${ }^{\text {i } M a g o o n, ~ C ., ~ V i l l a r s, ~ K ., ~ E v a n s, ~ J ., ~ H i c k e y, ~ B ., ~ S a y r e, ~ A ., ~ T u t i n o, ~ C ., ~ a n d ~ S w a p, ~ R . J ., ~ " W a t e r ~ S u p p l y ~ a n d ~ T r e a t m e n t ~}$ Design in Rural Belize: A Participatory Approach to Engineering Action Research," in International Journal for Service-Learning in Engineering, 5, no. 1 (2010): 47-63.

${ }^{i i}$ Brown-Glazner, R., Gutierrez, V., and Heil, E., "Engaging people, not projects: Redefining the standards of service-learning through a community led project in Tshapasha, South Africa," in Virginia Policy Review, 3, no. 3 (2010): 5-9.

iii Mavhunga, C. and Dressler, W., “On the Local Community: The Language of Disengagement?” in Conservation and Society, 5, no. 1 (2007): 44-59.

iv Tapela, B., Büscher, B., Maluleke, L., Twine, W., and Steenkamp, C., "Guidelines for negotiating social research in communities living adjacent to transboundary protected areas: Kruger National Park," (Johannesburg: University of Johannesburg, 2009).

"Edejer, T. T. E., "North-south research partnerships: The ethics of carrying out research in developing countries," in BMJ: British Medical Journal, 319, no. 7207 (1999): 438-441.

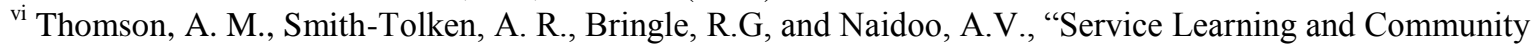
Engagement: A Comparison of Three National Contexts." in Voluntas: International Journal of Voluntary \& Nonprofit Organizations, 22, no. 2, (2010): 214-237.

vii Magoon, C., et. al., "Water Supply and Treatment Design in Rural Belize: A Participatory Approach to Engineering Action Research," 47-63.

viii Ermilio, J., Water for Waslala, "What will the pigs eat?" Last modified February 24, 2011 http://waterforwaslala.wordpress.com/2011/02/24/what-will-the-pigs-eat/

ix Sarlo, R. and Saboe, D., "Finding Sustainable Solutions to the Digital Divide in Semi-Urban Honduras," in International Journal for Service Learning in Engineering, 5, no. 1 (2010): 170-188.

${ }^{x}$ Wang, C. "Photovoice: A Participatory Action Research Strategy Applied to Women's Health." in Journal of Women's Health, 8, no. 2, (1999): 185-192

${ }^{\mathrm{xi}}$ Wang, C., "Youth Participation in Photovoice as a Strategy for Community Change," in Journal of Community Practice, 14, no. 1, (2006): 147-161

${ }^{x i i}$ Heil, E., Nengwenani, D., et. al. "Student-led, Community Driven Improvement of the Drinking Supply in a Rural Village in South Africa," in International Journal for Service Learning in Engineering, 5, no. 1 (2010): 94-110.

xiii Netshandama, V., "Quality Partnerships: The Commuity Stakeholder's View.” in Gateways: International Journal of Community Research and Engagement, 3 (2010): 70-87.

${ }^{\text {xiv }}$ Duffy, L., "Step-by-Step We are Stronger: Women's Empowerment Through Photovoice," in Journal of Community Health Nursing, 28, no. 2 (2011): 105-116.

${ }^{\mathrm{xv}}$ Moffit, P., and Vollman, A. R., "Photovoice: Picturing the Health of Aboriginal Women in a Remote Northern Community," in Canadian Journal of Nursing Research, 36, no. 4, (2004): 189-201

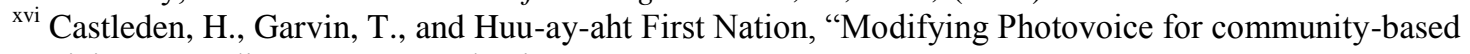
participatory Indigenous Research,” in Social Science and Medicine, 66, no. 6 (2008): 1393-1405
} 
${ }^{\text {xvii }}$ Maclean, K., Woodward, E., "Photovoice Evaluated: An Appropriate Visual Methodology for Aboriginal Water Resource Research," in Geographical Research, 51, no. 1 (2013): 94-105.

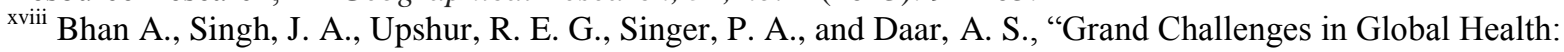
Engaging Civil Society Organizations in Biomedical Research in Developing Countries," in PLoS Medicine, 4, no. 9 (2007): 1456-1459.

${ }^{\text {xix }}$ Bhan A., et. al., "Grand Challenges in Global Health: Engaging Civil Society Organizations in Biomedical Research in Developing Countries," 1456-1459.

${ }^{\mathrm{xx}}$ Christens, B., "Targeting Empowerment in Community Development: A Community Psychology Approach to Enhancing Local Power and Well-Being," in Community Development Journal, 47, no. 4, (2012): 538-554.

${ }^{x x i}$ Bhan A., et. al., "Grand Challenges in Global Health: Engaging Civil Society Organizations in Biomedical Research in Developing Countries," 1456-1459.

xxii Sarlo, R. et. al., "Finding Sustainable Solutions to the Digital Divide in Semi-Urban Honduras," $170-188$.

xxiii Morgan, D., "Focus Groups," in Annual Review of Sociology, 22 (1996): 129-152

${ }^{x x i v}$ Wang, C. "Photovoice: A Participatory Action Research Strategy Applied to Women's Health."

${ }^{x x v}$ Reed, M., "Guess who's (not) coming for dinner: Expanding the terms of public involvement in sustainable forest management," in Scandinavian Journal of Forest Research; 25, no. 9 (2010): 45-54.

${ }^{x x v i}$ Mavhunga, C. et. al., "On the Local Community: The Language of Disengagement?" 44-59.

${ }^{x x v i i}$ Reed, M., "Guess who's (not) coming for dinner: Expanding the terms of public involvement in sustainable forest management," 45-54.

xxviii Duffy, L., “Step-by-Step We are Stronger: Women's Empowerment Through Photovoice,” 105-116.

${ }^{x x i x}$ Brown-Glazner, R., et. al., "Engaging people, not projects: Redefining the standards of service-learning through a community led project in Tshapasha, South Africa," 5-9.

${ }^{\mathrm{xxx}}$ Sarlo, R. et. al., "Finding Sustainable Solutions to the Digital Divide in Semi-Urban Honduras," $170-188$.

xxxi Morgan, D., "Focus Groups," 129-152

${ }^{\text {xxxii }}$ Fern, E., "The Use of Focus Groups for Idea Generation: The Effects of Group Size, Acquaintanceship, and Moderator on Response Quantity and Quality," in Journal of Marketing Research, 19 (1982): 1-13

xxxiii Fern, E., "The Use of Focus Groups for Idea Generation: The Effects of Group Size, Acquaintanceship, and Moderator on Response Quantity and Quality," 1-13

${ }^{\text {xxxiv }}$ Bourke, L., "Reflections on Doing Participatory Research in Health: Participation, Method and Power," in International Journal of Social Research Methodology; 12, no. 5 (2009): 457-474.

${ }^{\mathrm{xxxv}}$ Gobar, A., "Where Asset Building and Community Development Converge," in Researcher: An Interdisciplinary Journal; 22, no. 2, (2009): 1-28.

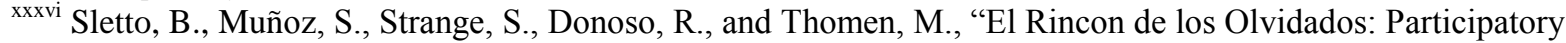
GIS, Experiential Learning and Critical Pedagogy in Santo Domingo, Dominican Republic," in Journal of Latin American Geography, 9, no. 3 (2010): 112-135.

xxxvii Mohamad, N., Abu Talib, N., Bin Ahmad, M., Mad Shah, I., Leong, F., and Shakil, M., "Role of Community Capacity Building Construct in Community Development." in International Journal of Academic Research, 4, no. 1 (2012): 172-176.

xxxviii Christens, B., "Targeting Empowerment in Community Development: A Community Psychology Approach to Enhancing Local Power and Well-Being," 538-554.

${ }^{\text {xxxix }}$ Mohamad, N., et. al., "Role of Community Capacity Building Construct in Community Development." $172-$ 176.

${ }^{x l}$ Brown-Glazner, R., et. al., "Engaging people, not projects: Redefining the standards of service-learning through a community led project in Tshapasha, South Africa," 5-9.

xli Sarlo, R. et. al., "Finding Sustainable Solutions to the Digital Divide in Semi-Urban Honduras," 170-188. 